\title{
Estimation of illicit drug use in the main cities of Colombia by means of
}

urban wastewater analysis

Lubertus Bijlsma ${ }^{\mathrm{a}}$, Ana M. Botero-Coy ${ }^{\mathrm{a}}$, Rolando J. Rincón ${ }^{\mathrm{b}}$, Gustavo A. Peñuela ${ }^{\mathrm{c}}$, Félix Hernández ${ }^{\mathrm{a} *}$

${ }^{a}$ Research Institute for Pesticides and Water (IUPA), University Jaume I, Castellón, Spain

${ }^{\mathrm{b}}$ Chemistry Department, Faculty of Sciences, University Antonio Nariño, Colombia

${ }^{c}$ Grupo GDCON, Facultad de Ingeniería, Universidad de Antioquia, 70 \# 52 - 21, Medellin, Colombia

* Author for correspondence: felix.hernandez@uji.es, Tel +34 964 387366, Fax +34 964 387368 


\begin{abstract}
Wastewater-based epidemiology (WBE) relies on the principle that traces of compounds, which a population is exposed to or consume, are excreted unchanged or as metabolites in urine and/or faeces, and ultimately end up in the sewer network. Measuring target metabolic residues i.e. biomarkers in raw urban wastewater allows identifying the exposure or use of substances of interest in a community. Up to date, the most popular application of WBE is the estimation of illicit drug use and studies have been made mainly across Europe, which has allowed estimating and comparing drug use in many European cities. However, until now a comprehensive study applying WBE on the most frequently consumed illicit drugs has not been performed in South American countries. In this work, we applied this approach to samples from Colombia, selecting two of the most populated cities: Bogotá and Medellin. Several biomarkers were selected to estimate drug use of cocaine, cannabis, amphetamine, methamphetamine, MDMA (ecstasy), heroin and ketamine. Composite samples (24-h) were collected at the corresponding municipal wastewater treatment plants. Sample treatment was performed at location by applying solid phase extraction (SPE). Before SPE, the samples were spiked with appropriate isotope labeled internal standards. In parallel, samples (spiked with the analytes under study at two concentration levels) were also processed for quality control. Analysis of influent wastewater was made by liquid chromatography-tandem mass spectrometry, with triple quadrupole analyzer. Data shown in this paper reveal a high use of cocaine by the population of the selected Colombian cities, particularly from Medellin, while the use of other illicit drugs were low. The relevance of using quality control samples, particularly in collaborative studies, as those presented in this work, where research groups from different countries participate and where the samples had to be shipped overseas, is highlighted in this paper.
\end{abstract}

\title{
Keywords
}

Wastewater-Based Epidemiology, LC-MS/MS, Drugs of Abuse, Consumption, Latin America 


\section{Highlights}

- Wastewater-based epidemiology was applied for the first time in Colombia

- Inclusion of control samples, previous to shipment, assures the quality of the data

- Emphasis was made on evaluating uncertainties associated with this study

- Cocaine was the most consumed illicit drug, particularly in Medellin 


\section{INTRODUCTION}

The estimation of illicit drug use at the population level through wastewater analysis i.e. wastewater-based epidemiology (WBE), has been presented as a complementary data source to other monitoring tools such as surveys, treatment demand and law enforcement data. The approach has shown great progress, and recent efforts have been put in data triangulation with other sources (Been et al., 2016, 2015) and the statistical analysis of the data produced (Salvatore et al., 2015), especially in large comparison studies. Despite several limitations, it has shown clear advantages, which have been widely recognized (Castiglioni et al., 2014; EMCDDA, 2015a). Hence, WBE demonstrates high potential and is a rapidly developing scientific discipline.

New WBE applications have been presented for alcohol, tobacco and new psychoactive substances (Kinyua et al., 2015; Reid et al., 2011; Rodriguez-Alvarez et al., 2014), but, up till now, the most popular application of WBE is the estimation of illicit drug use in a community. The first studies were presented in Italy (Zuccato et al., 2005) and promptly expanded through Europe, resulting in a joint effort to harmonize the approach coordinated by the Sewage Analysis CORe group Europe (SCORE) ("http://score-cost.eu/"). This has allowed the estimation and comparison of drug use over time in up to 42 European cities (Ort et al., 2014; Thomas et al., 2012). However, WBE has also been implemented in other continents such as Australia (Irvine et al., 2011; Prichard et al., 2012) and North America (Banta-Green et al., 2009; Devault et al., 2014; Metcalfe et al., 2010; Subedi and Kannan, 2014) and is starting to be applied in Asia (Khan et al., 2014; Kim et al., 2015; Lai et al., 2013). WBE has also been applied once in South America (Brazil) for the estimation of cocaine consumption (Maldaner et al., 2012).

Although various facets still requires further optimization, the main uncertainties have been identified and recommendations have been made to minimize errors related to sample collection (Ort et al., 2010), in-sewer and in-sample stability (McCall et al., 2016), the estimation of the population size contributing to the catchment area, and backcalculation procedures (Castiglioni et al., 2013; Lai et al., 2011). Furthermore, working according a common "best-practice" protocol has been recommended in order to assure quality and produce data that allow comparison between studies. Within this protocol the importance of performing reliable analytical measurements and participation in intercomparison exercises has also been emphasized (Castiglioni et al., 2013). 
In this work we present the first comprehensive study on the use of several frequently consumed illicit drugs in Latin America by WBE, specifically in Colombia, selecting two of the main cities: Bogotá and Medellin. The harmonized "best-practice" protocol established by Castiglioni et al. 2013 (Castiglioni et al., 2013) has been followed to ensure high quality and comparable data. Furthermore, the authors participated in the same and previous years, with success, in the inter-laboratory tests organized by SCORE using the analytical methodology developed by Bijlsma et al. 2014 (Bijlsma et al., 2014). The study consisted of a close collaboration between different research groups from Colombia and Spain. Sample collection and solid-phase extraction (SPE) was performed in Colombia and elution of the SPE cartridges and analysis by liquid chromatographytandem mass spectrometry (LC-MS/MS) was performed in Spain. Special attention has been paid to ensure the quality during sample treatment and analytes stability while shipping the SPE cartridges to Spain. To this aim, samples were spiked with appropriate isotope labeled internal standards (ILIS) before SPE, and Quality Controls (QCs) were prepared from wastewater samples collected during the week (not weekends) and fortified at two concentration levels with the compounds under study (cocaine, benzoylecgonine, THC-COOH, amphetamine, methamphetamine, MDMA, 6-MAM, and ketamine). QCs were analyzed in the same sequence together with the corresponding non-fortified samples and the rest of samples collected daily during one whole week. 


\section{MATERIALS AND METHODS}

\subsection{Target analytes}

In total, 8 drugs and/or main metabolites were selected for this study: amphetamine, methamphetamine, 3,4-methylenedioxymethamphetamine (MDMA, or ecstasy), cocaine, benzoylecgonine (BE), 11-nor-9-carboxy- $\Delta^{9}$-tetrahydrocannabinol (THC-COOH), 6-monoacetylmorphine (6-MAM) and ketamine. ILIS were used as surrogate for quantification: amphetamine- $\mathrm{d}_{6}$, methamphetamine- $\mathrm{d}_{5}$, MDMA- $\mathrm{d}_{5}$, cocaine- $\mathrm{d}_{3}$, benzoylecgonine- $\mathrm{d}_{3}$, THC-COOH- $\mathrm{d}_{3}, 6-\mathrm{MAM}^{-} \mathrm{d}_{6}$ y ketamine- $\mathrm{d}_{4}$. More details on chemicals and materials can be found elsewhere (Bijlsma et al., 2014).

\subsection{Sample collection}

The 24-h composite influent wastewater (IWW) samples were collected daily over seven consecutive days in 2015. In Bogotá, samples were taken using a volumeproportional sampling mode (every 2,500 $\mathrm{m}^{3}$ ), starting on Wednesday March 11th and ending on Tuesday March $17^{\text {th }}$ (auto-sampler Endress-Hauser). For an average flow rate of wastewater of $350,000 \mathrm{~m}^{3} /$ day (see next section), around 140 sample aliquots of $200 \mathrm{~mL}$ were collected every 2,500 $\mathrm{m}^{3}$, approximately every $10 \mathrm{~min}$. In Medellin, sample collection was performed using a time-proportional sampling mode (every $30 \mathrm{~min}$ ) starting on Wednesday June 24th and ending on Tuesday, June 30th. In both cases, samples were collected in high-density polyethylene bottles and transported to the corresponding laboratories for sample treatment. Upon reception in the laboratory, samples were immediately stored in the dark at $-20^{\circ} \mathrm{C}$ until filtration and extraction. Concentrations of chemical oxygen demand (COD) and biological oxygen demand (BOD) were routinely measured of each sample. Flow rate data of each day was also recorded (Table S1 of Supplementary Material) and used to calculate daily loads.

\subsection{Characteristics of the wastewater treatment plants and studied areas}

The analyzed samples were collected in two of the main cities of Colombia (Bogota, Department of Cundinamarca, and Medellin, department of Antioquia). A total of 14 IWW samples were taken from the "Salitre" and "San Fernando" wastewater treatment plants (WWTP) serving Bogotá and Medellin, respectively. 
The WWTP of Salitre treats wastewater from around 2.5 million inhabitants. It is located in the Northwest of Bogotá, and collects water from several districts: Santa Fe, Teusaquillo, Chapinero, Barrios Unidos, Usaquén, Suba, Fontibón and Engativá (Figure S1). After treatment, the effluent wastewater is discharged in the Bogotá river. The average flow rate of wastewater treated by the WWTP over one year is $4 \mathrm{~m}^{3} / \mathrm{s}$ (ca. $350,000 \mathrm{~m}^{3} /$ day), with a removal efficiency of $40 \%$ BOD and $60 \%$ of suspended solids ("http://www.acueducto.com.co/").

The WWTP of San Fernando is located in the South of Medellin. It receives wastewater from around 600,000 inhabitants living in several districts of the Department of Antioquia, such as Itagui, Envigado, Sabaneta, La Estrella, Caldas and the South of Medellin (Figure S1). The average flow rate of wastewater treated by the WWTP over one year is $1.8 \mathrm{~m}^{3} / \mathrm{s}$ (ca. 150,000 $\mathrm{m}^{3} /$ day), with a removal efficiency of $80-85 \%$ BOD and $85 \%$ of suspended solids ("http://www.epm.com.co/")

It is noteworthy that the wastewater samples collected comes from catchment areas where several schools, universities, hospitals, business offices, shops, entertainment venues and clubs are located, and in a minor extent some industries. Therefore, number of commuters contributing to the samples in these two cities may vary considerable along the day.

\subsection{Analytical methodology}

The samples were analyzed for the aforementioned compounds using a validated method previously developed by our group. Sample treatment and specific information on instrument operating conditions, both chromatographic and MS, and on method validation can be found elsewhere (Bijlsma et al., 2014). Sample treatment was performed in the laboratories of the University of Antonio Nariño and the University of Antioquia. Briefly, $25 \mathrm{~mL}$ of the influent wastewater samples, previously filtered through a mixed cellulose ester membrane filter, were spiked with $200 \mu \mathrm{L}$ of mixed ILIS solution (10 $\mu \mathrm{g} / \mathrm{L}$ ) and diluted to $100 \mathrm{~mL}$ with HPLC water. SPE was performed using Oasis HLB cartridge $(60 \mathrm{mg})$ and after drying under vacuum, the cartridges were shipped to Spain for elution and analysis. The analytes were eluted with $5 \mathrm{~mL}$ methanol. The extracts were evaporated and reconstructed in $1 \mathrm{~mL} \mathrm{10 \%} \mathrm{methanol} \mathrm{aqueous} \mathrm{solution.} \mathrm{For} \mathrm{amphetamine}$ and amphetamine-type stimulants (ATS) an additional clean-up was applied to improve 
the performance of the method. Aliquots of $0.5 \mathrm{~mL}$ of the HLB extracts were 10 times diluted with HPLC water acidified at $\mathrm{pH}$ 2, and loaded onto an Oasis MCX cartridges $(150 \mathrm{mg})$. The cartridges were washed with $5 \mathrm{~mL}$ of acidified methanol $(\mathrm{pH} 2)$ and vacuum dried. Elution was performed with $8 \mathrm{~mL} 2 \%$ ammonia solution in methanol. The extracts were evaporated and reconstructed in $0.5 \mathrm{~mL} 10 \%$ methanol aqueous solution. In addition, $10 \mathrm{mg}$ of primary secondary amine (PSA, 40-60 $\mu \mathrm{m}$ ) was added to the final extracts. After centrifugation, $3 \mu \mathrm{L}$ of the supernatants (MCX extracts) and $3 \mu \mathrm{L}$ of the HLB extracts were directly injected into the UHPLC-MS/MS system. Chromatographic separation of the compounds was achieved using an Acquity UPLC BEH $\mathrm{C}_{18}$ column and an optimized gradient using methanol: water $(5 \mathrm{mM}$ ammonium acetate, $0.01 \%$ formic acid). A Xevo TQS triple quadrupole mass spectrometer was operated in positive ionization mode. Quantitative analysis were performed under selected reaction monitoring (SRM) acquiring three transitions per target compound, and using relative areas corresponding to each analyte ILIS. All data were acquired and processed using MassLynx v 4.1 software (Waters, Manchester, UK).

\subsection{Normalization and estimation of drug use}

Concentrations of the parent drugs and/or metabolites were calculated into amount of illicit drug used (in mg/day/1000 inhabitants). For these back-calculations, the knowledge of several key parameter is required: i) the stability of the analytes, ii) the flow rate of the wastewater stream $\left(\mathrm{m}^{3} /\right.$ day) to transform concentrations into mass loads (mg/day), iii) the number of inhabitants that are served by the WWTP (van Nuijs et al., 2011b). In addition, a correction factor is required to back-calculate from mass loads into amount of used illicit drug. This is dependent on the percentage of illicit drug excreted as parent compound and/or metabolite(s). Unfortunately, human pharmacokinetic data is limited for most of the main illicit drugs, and as a consequence high biases can be associated to the use of improper 'not refined' correction factors (Castiglioni et al., 2014). Until now, only for cocaine correction factors are refined and the associated uncertainty reduced by taking into account all the pharmacokinetics data available and the metabolic differences that can occur according to the route of administration. In this work, measured mass loads of BE were multiplied with a factor of 3.59, as proposed by Castiglioni et al. 2013, assuming that the mean BE excretion was $29 \%$ of a cocaine dose (Castiglioni et al., 
2013). The corrected loads were further used in the back-calculations of cocaine use in the population.

To compare cities of different sizes, mass loads were normalized by the population size of the catchment (mg/day/1000 inhabitants). The estimation of the number of people contributing to the wastewater samples was made in this work by different ways: census data (collected from information provided by the WWTPs ("http://www.acueducto.com.co/", "http://www.epm.com.co/") and COD and BOD data measured during the sampling period. 


\section{RESULTS AND DISCUSSION}

\subsection{Concentrations of illicit drugs in raw wastewater}

Table S2, shows the concentrations (ng/L) of the target compounds found in the influent wastewater samples from both Bogotá and Medellin. Cocaine and its metabolite BE showed the highest concentration values in both cities. Particularly, BE exceeded $1000 \mathrm{ng} / \mathrm{L}$ (1 ppb) in all samples from Bogotá and $4000 \mathrm{ng} / \mathrm{L}$ (4 ppb) in all samples from Medellin. The main metabolite of cannabis (THC-COOH) was found in all samples at concentrations around 200 and 300 ng/L for Bogotá and Medellin, respectively. MDMA was also found in all samples from Bogotá, at concentrations between 12 and $68 \mathrm{ng} / \mathrm{L}$, but scarcely detected in Medellin (only three samples at concentrations around $10 \mathrm{ng} / \mathrm{L}$ ). Ketamine was detected in all but at low concentrations, always below $32 \mathrm{ng} / \mathrm{L}$. Amphetamine, methamphetamine and 6MAM were not detected in any sample.

As illustrative examples of positive samples, Figure 1 shows UHPLC-MS/MS chromatograms (quantification transition (Q)) for ketamine, THC-COOH, cocaine and BE for wastewater samples from the two cities. The identity of the compounds could be confirmed in all cases with three transitions acquired by compliance of the two ion ratios available within the tolerance admitted $( \pm 30 \%)$ and retention time $( \pm 0.2 \mathrm{~min})$ (SANCO, 2013).

\subsection{Normalization of mass loads and estimation of drug use}

It is essential to know the population size of the catchment area in order to normalize mass loads (mg/day/1000 inhabitants) and compare results from different sites. Different methods can be used to estimate the number of people contributing to the sampled wastewaters, e.g. census data and data based on measuring hydrochemical parameters such as biological oxygen demand (BOD), chemical oxygen demand (COD), nitrogen $(\mathrm{N})$ and phosphorus $(\mathrm{P})$, using specific loads for these parameters i.e. per-capita loads from domestic activity (Andreottola et al., 1994). However, the reliability of population estimates depend on factors that cannot easily be controlled, e.g. the composition of sewage (industrial, domestic or mixed) that influence the hydro-chemical parameters, the accuracy of census data, the quality of the measured flow data and the method itself used to calculate population equivalents. An interesting discussion on 
estimation of the number of people present in an specific area -the de facto populationand on the importance of population movements can be found in (Charles-Edwards and Bell, 2013; O'Brien et al., 2013). The best option available, even if not ideal, is to compile estimates based on different methods and to choose the most reliable one using expert judgement of WWTPs personnel. This has been the procedure adopted in recent European monitoring campaigns (Ort et al., 2014; Thomas et al., 2012). In this work, census data were in rather good agreement with estimations made from BOD and COD in the WWTP of San Fernando-Medellin (600,000 people from census; 730,000 \pm 120,000 from BOD; $640,000 \pm 98,000$ from COD). In the case of the WWTP of Salitre-Bogotá, census data was a bit higher (2,5 million people) than that estimated from $\operatorname{BOD}(1,850,000 \pm 180,000)$ and $\operatorname{COD}(1,700,000 \pm 125,000)$. Finally, mass loads of both cities were normalized using their corresponding census data.

In order to get insight in patterns of drug use within the cities under study, daily loads (g/day) were calculated by multiplying measured concentrations (ng/L) with the corresponding daily values of the flow ( $\mathrm{m}^{3} /$ day) (Table S3). Data were then normalized by population size (1000 inhabitants) to allow easier comparison with different cities. Figure 2 and Table 1 show the normalized daily mass loads of cocaine and BE as well as MDMA, THC-COOH and ketamine. Normalized mass loads of cocaine and BE were fairly stable throughout the week with only a slight increase in the weekend samples. This would reflect that consumers take this drug regularly and not only during weekends and is in contrast with other studies, where higher loads were clearly found for BE during the weekend compared to weekdays (Lai et al., 2011; Metcalfe et al., 2010; Ort et al., 2014; Thomas et al., 2012). Except for two studies, one performed in Martinique (Caribbean area) (Devault et al., 2014), and another in Hong Kong (Lai et al., 2013) where obvious differences were neither observed. Similarly, THC-COOH did not appear to increase significantly during weekends, remaining stable throughout the week, whereas for MDMA a small increase in the weekends was observed. These findings are in line with data reported in other cities (Irvine et al., 2011; Lai et al., 2011; Ort et al., 2014; Thomas et al., 2012; Yargeau et al., 2014). Ketamine was detected at low concentration levels, in some cases around or below the LOQ, which impeded to the ability to determine any trend.

Comparison of consumption of illicit drugs with other studies is sometimes complicated when authors use different correction factors of urine excretion rates. Back- 
calculation for cocaine consumption was, for example, initially made using a $45 \%$ excretion rate of BE (van Nuijs et al., 2011a) and got later refined to 38\% (Thomas et al., 2012) and 29\% (Castiglioni et al., 2013), integrating the different administration routes of cocaine. Therefore, careful selection of these correction factors is required to ensure the reliability and comparison of results between different studies (Castiglioni et al., 2016). Hence, it is desirable to agree on and set these values. However, the lack of studies on human metabolism makes the evaluation of the uncertainties related troublesome, and thus the establishment of correction factors for human excretion. In this study, we preferred not to use correction factors similar to two recent studies (Khan et al., 2014; Ort et al., 2014). The only exception was for the back calculation of cocaine consumption, which was estimated with and without correction factor. In any case, special precaution should be taken regarding this matter when comparing data.

Table 2 shows average estimates of cocaine consumption for the two cities. Backcalculations for cocaine were done based on BE loads making use of a correction factor of 3.59 that takes into account an average urine excretion rate of $29 \%$ (see Materials and Methods. Normalization and estimation of drug use). The highest weekly average cocaine consumption were observed in Medellin with $3022 \mathrm{mg} /$ day/1000inh. This was above European cities, even those with highest rates of consumption such as Amsterdam and Antwerp where the estimated cocaine reaches up to $2000 \mathrm{mg} /$ day/1000inh (Thomas et al., 2012). In the case of Bogotá, the average consumption of cocaine was 742 $\mathrm{mg} /$ day/1000inh similar to the values found in Europe for Brussels, Castellón, Milan, Paris and Santiago de Compostela, but lower than those estimated in for example Barcelona and London (Thomas et al., 2012). Colombia is known as one to the main cocaine-producing countries (UNODC, 2015) and the purity of street cocaine is surely higher compared to Europe (average in 2013, 20-60\%) ("http://www.emcdda.europa.eu/data/stats2015") and the USA (average in 2009, 50\%) ("https://www.unodc.org/documents/data-and-analysis/tocta/4.Cocaine"), as purity levels tend to decline along the trafficking chain (UNODC, 2015). It is maybe therefore not surprisingly that it is the drug with highest prevalence in Bogotá and Medellin.

Cocaine use was also evaluated by directly using loads of BE, without applying correction factors. In comparison with the wide study performed in 42 cities from 21 European countries (Ort et al., 2014) reporting data of three consecutive years 2011 2013, including the data of Thomas et al. of the year 2011 (Thomas et al., 2012), average 
loads of BE in Bogotá (207mg/day/1000inh) is similar to the European cities we previously mentioned, and lower than Amsterdam, Barcelona, London, Valencia or Zurich, all with average daily loads above $400 \mathrm{mg} / \mathrm{day} / 1000 \mathrm{inh}$. On the contrary, average loads of BE on Medellin (845mg/day/1000inh) was higher than all studied European cities, with the only exception of the value found in Antwerp Zuid in 2013 that was of the same order. When comparing this data with countries or cities from outside Europe, the use of cocaine in Australia (Irvine et al., 2011; Lai et al., 2011) South Korea (Kim et al., 2015) and China (Khan et al., 2014; Lai et al., 2013) was lower, whereas average loads of BE in Brazil (Maldaner et al., 2012) and Martinique (Devault et al., 2014) (approximately $450 \mathrm{mg} /$ day/ 1000inh, after re-calculation) were higher than in Bogotá, but generally did not exceed those observed in Medellin.

The average loads for the cannabis biomarker THC-COOH in Bogota and Medellin (33 mg/day/ 1000inh and $47 \mathrm{mg} /$ day/ 1000inh, respectively) were about the same order as those found in Bratislava, Milan, Sarajevo, Zagreb, but lower than those reported in Athens, Antwerp Zuid, Barcelona, Eindhoven, Paris, and Utrecht, all with values near or slightly above 100 (Ort et al., 2014). In the referenced article, the highest values reported for THC-COOH corresponded to Amsterdam and Novi Sad (Croatia) up to 348 mg/day/1000inh. Cannabis use in Australia (Lai et al., 2011) was lower, whereas that of Martinique (Devault et al., 2014) was considerably higher with average loads of 6.5 and $224 \mathrm{mg}$ THC-COOH/day/1000inh, respectively. In both cases, we re-calculated data for comparison using a single correction factor of 152 as was done by the corresponding studies. In China, THC-COOH was not detected in any wastewater sample (Khan et al., 2014). However, it is worth mentioning that several challenges has been associated to the chemical analysis of cannabis metabolites, and also to the potential for these substances to partition to particulate matter, which could reduce their availability in wastewater. Therefore, special precaution should be taken when interpreting the results, and more research is recommended (Castiglioni et al., 2016).

Loads of MDMA in Colombia were very low in comparison with cannabis and BE, with mean values of 1.5 and $4.4 \mathrm{mg} / \mathrm{day} / 1000 \mathrm{inh}$. These values are in line with those reported in cities such as Lisbon, Milan, Oslo, Valencia, Zagreb (Ort et al., 2014), and the low levels observed in China (Khan et al., 2014). However, MDMA values are significantly lower than those reported in Australia (Irvine et al., 2011; Lai et al., 2011) and Canada (Metcalfe et al., 2010; Yargeau et al., 2014) and the European cities of 
Amsterdam, Antwerp, Barcelona, London, or Zurich (Ort et al., 2014), whose wastewater often exceed $30 \mathrm{mg} / \mathrm{day} / 1000 \mathrm{inh}$. In Hong Kong and Martinique, no detectable concentrations were found (Devault et al., 2014; Lai et al., 2013).

Loads of ketamine in wastewater were quite low, in the order of 1.5 and 4.0 mg/day/1000inh for Medellin and Bogotá, respectively. Concentrations or loads of this drug and its metabolite norketamine has mainly been reported in Asia (Khan et al., 2014; Lai et al., 2013; Lin et al., 2010), suggesting its use particularly in this region, e.g. in China ketamine loads varied from $<1.1$ to $117 \mathrm{mg} /$ day/1000inh (Khan et al., 2014). In Europe, the recreational use of ketamine has also been reported (EMCDDA, 2015b), and is reflected by some positive findings of the unchanged drug (Baker and KasprzykHordern, 2011; Bijlsma et al., 2012; van Nuijs et al., 2014) and its metabolite (Bijlsma et al., 2013) in wastewater. The latter can directly be linked to human consumption.

No detectable concentrations were found for 6-MAM, suggesting that heroin use could possibly be considered as low. However, precaution is required in the interpretation of this data, as it is an exclusive but minor metabolite of heroin and stability in-sample and in-sewer is low (McCall et al., 2016)(Castiglioni et al., 2016). High loads of methamphetamine have been reported in Australia (Irvine et al., 2011; Lai et al., 2011), Asia (Khan et al., 2014), North and East of Europe (Ort et al., 2014) and North America (Banta-Green et al., 2009; Chiaia-Hernandez et al., 2011), but in Colombia methamphetamine and amphetamine were not detected, indicating a limited use of these drugs.

\subsection{Data comparison with other sources}

It is worth noting that the estimations on drug use in this work are mostly in good in agreement with information obtained by other sources and with previous data reported on drug consumption in Colombia. This fact supports the usefulness and applicability of WBE to estimate drug use in real-time. Although the estimated global production of cocaine has declined in South America, practically all of the world's cocaine is still produced in three of those countries (Colombia, Peru and Bolivia). As an example, cultivation of coca bush in Colombia halved between 2007 and 2012. Despite this decline, South America has seen an increase in terms of consumption of cocaine (including crack) (UNODC, 2014). It is therefore not surprising that cocaine is one of the most consumed drugs by the population of Bogotá and Medellin. 
A significant component of cocaine use in South America, and particularly in Colombia, is the smoking of various forms of cocaine, including crack-cocaine (locally known as bazuco) as well as other crude forms of cocaine base (UNODC, 2014). Bazuco was found the most commonly consumed form within the group of "smoked" cocaine in Medellin (Castaño Pérez et al., 2013). Around 70\% of 109 bazuco samples analysed contained between 20 to $50 \%$ pure cocaine, with an average of 37\% (Sabogal-Carmona and Urrego-Novoa, 2012).

In agreement with the high consumption of cocaine estimated in this study, is the fact that this drug was by far the main cause of the intoxication (185 cases, including bazuco), in Antioguia (Medellin) ("http://www.odc.gov.co/consumo-drogas-antioquia"). According to this report on intoxications by psychoactive substances treated in medical emergencies in the Antioquia Department, cocaine was followed by scopolamine (84) and alcohol (79), and to a minor degree cannabis (13), amphetamines (2) and ecstasy (2). Cocaine was also reported as the third drug used by teenagers ( $7.8 \%$ of cases) from Medellin to promote and facilitate sexual relations, after alcohol $(80 \%)$ and cannabis (32\%). Ecstasy, although widely used in the 80's and 90's as the "drug of love", was less used by teenagers $(5.7 \%)$. Ketamine and methamphetamine (crystal) were also reported, although with low prevalence (between 1 and 2\%) (Castaño Pérez et al., 2012). Data reported in 2014 by the Department of Antioquia, where the WWTP of San Fernando (Medellin) is located, showed similar trends as the highest prevalence in schoolchildren corresponded to alcohol (63\%), tobacco (24\%) and energy drinks (26\%). The prevalence of cannabis $(10.8 \%)$ and cocaine $(4.6 \%)$ were above the national average of $7 \%$ and $2.8 \%$, respectively ("http://www.odc.gov.co/consumo-drogas-antioquia"). It is therefore not surprising that cocaine consumption in Medellin, estimated from analysis of wastewaters is high, although one should take into account the uncertainties associated to WBE (see the following sections) and the limitations derived from the fact that only one week was monitored.

According to a recent survey conducted among university students in the four Andean countries, the annual prevalence of cannabis use ranged between $15.2 \%$ in Colombia to $3.6 \%$ in Bolivia. Cocaine use was high in Colombia (2.2\%) compared with Ecuador (1.1\%), Peru (0.5\%), and Bolivia (0.3\%). ATS use was reported in Colombia $(0.9 \%)$, Ecuador $(0.7 \%)$ and Peru (0.5\%). Comparing the trends between 2009 and 2012 there has been an overall increase in cannabis use (from an average of $4.8 \%$ in 2009 to 
$7.9 \%$ in 2012), a stable trend with regard to cocaine use and a small increase in the use of ATS (UNODC, 2014). The fact that MDMA has been detected in nearly all wastewater samples, although at low concentrations, implies that it is currently used by the people of Bogotá and Medellin, but in a much less extent than cocaine and cannabis.

Ketamine is considered a "dissociative anesthetic" used in powdered or liquid form. Despite its original design as human and, more commonly, veterinary anesthetic, ketamine has gained popularity as 'club drug' over the past few years. According to recent studies, ketamine is among the emerging drugs used in Medellin. It is popularly known as "keta", "Vitamin K", "Special K", or "Super K" is consumed preferentially in bars and discos, together with other synthetic drugs as LSD, MDMA, phencyclidine and alkyl nitrites (i.e. poppers) (Castaño Pérez et al., 2013). According to data reported in 2015 from the Colombian Early Warning System, ketamine has been one of the most frequent new psychoactive substances (NPS) recently detected in Colombia. In addition to its direct use, it can also be employed as adulterant in ecstasy and 2CB (2,5-dimethoxy-4bromophenethylamine), a synthetic hallucinogen, also used as NPS in Colombia ("http://www.odc.gov.co/nuevas-sustancias-psicoactivas-colombia"). 2CB is also known as "cocaína rosada" or "pink cocaine", and has been considered as the world's most expensive illicit drug used by the upper-class party scene ("http://elsiglo.com/cronicaroja/cocaina-rosada-droga-cara-mundo/23863634"). The fact that ketamine has been found and quantified in all wastewater samples, also indicates that its use is not sporadic.

The use of heroin is an emerging reality in Colombia as it is being produced at high extent. The problems around the consumption of this drug have been noticed. However, it has been reported that heroin is rarely used as a single substance, and is commonly combined with cocaine (speedball), tobacco, cannabis, alcohol or sedatives (Castaño Pérez and Calderón Vallejo, 2012). As previously stated, we did not find its metabolite 6-MAM in wastewater. With the precautions mentioned on the interpretation of this data, it seems that the use of heroin in the Colombian cities under study is lower than the other compounds that have been discussed above.

\subsection{Uncertainties}

It is important to estimate and evaluate the uncertainty associated with the different steps of the WBE approach within this study. This will give critical insight in 
the validity and reliability of the results obtained and subsequent estimations made. Uncertainties are mainly related to sampling, stability of the compounds, analysis, population size and back-calculations (Castiglioni et al., 2013), with the highest errors generally associated with sampling, stability and population.

The WWTP of Bogotá applied a volume-proportional sampling strategy with intervals of 2,500 $\mathrm{m}^{3}$, whereas the WWTP of Medellin collected samples using a timeproportional sampling mode with intervals of $30 \mathrm{~min}$. Higher intervals would increase the uncertainty on the measurements, especially for the smaller catchment of Medellin. Therefore, flow-proportional sampling or short intervals are recommended (Ort et al., 2010). However, this is not always possible as it most often depends on the sampling devices installed at the WWTP.

A comprehensive review on in-sewer (i.e. transport in sewers) and in-sample stability has recently been published (McCall et al., 2016). In-sewer stability is difficult to manage, nevertheless, it has been estimated to be less than 10\% (Castiglioni et al., 2013). Yet, it has also been highlighted that more research is needed (Castiglioni et al., 2013; McCall et al., 2016). In-sample stability of the compounds can be better controlled and were reduced by storing the samples at $-20^{\circ} \mathrm{C}$ and loading them on SPE cartridges within one month in order to transport them as such to the laboratory for analysis.

As previously mentioned, the determination of the analytes was performed following a specific "best-practice" protocol, and the analytical methodology applied passed the inter-laboratory exercise. Furthermore, internal quality controls were analyzed within each sample batch to ensure the quality of the data produced (see section 3.4.). Therefore, it was expected that uncertainty associated to this step was notably reduced.

The population size and normalization of the data was calculated using the census data of both the catchment area of Bogotá (2,5 million people) and Medellin $(600,000$ people). This was chosen as the best option as the hydro-chemical parameters i.e. BOD and COD, may be influenced by the minor extend of industries within the catchment areas. Conversely, when using census data day-to-day variations cannot be taken into account (Lai et al., 2011). In this work, the close agreement between population estimations made from census data, from BOD and from COD, especially in the city of Medellin, led us to assume that uncertainty associated to this step was also rather low. 
Finally, uncertainties related to excretion rates were not considered as results are expressed as mass loads in wastewater.

\subsection{Quality control}

With each sample batch of seven samples, two quality controls (QC) were prepared in the sample preparation step, which was performed at the city of sampling i.e. Bogotá and Medellin. QCs consisted on a "blank" sample that was collected during the week (Tuesday) and that was spiked at two different concentration levels, 0.1 and $0.8 \mu \mathrm{g} / \mathrm{L}$. The seven samples corresponding to the whole week and the two QCs were passed through the HLB cartridges, vacuum dried and shipped to Spain for their analysis. A calibration curve with standards in solvent (including ILIS) was injected together with each batch of seven samples and two QCs.

We paid particular attention to guarantee the integrity of samples along this process, by analyzing two QCs for samples of Bogotá and another two QCs for the samples of Medellin. In Table 3 it can be seen that nearly all QCs recoveries (93\%, corresponding to 27 values out of 29 available data) were in the range of 60-140\% (SANCO, 2013), although the great majority were within a narrower range of $70-120 \%$ (83\% of the recoveries, corresponding to 24 out of 29). The "blank" non-spiked samples contained most of the compounds under study; therefore, the concentrations found in the "blanks" were subtracted from those measured in spiked samples in order to obtain recoveries. The calculation of recoveries in the case of $\mathrm{BE}$ was problematic due to the high concentrations found in the non-spiked samples. Therefore, only one data was available. In any case, the method had been satisfactorily validated for this compound (Bijlsma et al., 2014).

The ion intensity ratios ( $\mathrm{q}_{\mathrm{i}} / \mathrm{Q}$ ratio, where $\mathrm{q}_{\mathrm{i}}$ is the qualitative transition used for confirmation, and $\mathrm{Q}$ is the quantitative transition used for quantification purposes) were also calculated for the three transitions acquired ( $\mathrm{q}_{1} / \mathrm{Q}$ and $\left.\mathrm{q}_{2} / \mathrm{Q}\right)$ in the $\mathrm{QCs}$ analyzed, and their compliance with the reference standards (average q/Q ratio for all standards used in the calibration curve) was evaluated. The results confirmed the robustness of this approach for confirmation of the identity of the compounds, as all of them could be confirmed by at least one q/Q ratio (deviation < $30 \%$ ), and commonly by both ion ratios available (Table 3). The only exception was amphetamine in the sample of Medellin spiked at $0.1 \mu \mathrm{g} / \mathrm{L}$, where ion rations deviations were out of the $30 \%$ tolerance applied by 
the SANCO guidelines (SANCO, 2013). The non-compliance of q/Q ratio tolerance illustrates the difficulties for the determination of amphetamine at the lowest level, as it coincides with the LOQ of the method for this compound $(0.1 \mu \mathrm{g} / \mathrm{L})$ (Table S4). The restrictive SANCO guideline applied for pesticide residue analysis (SANCO, 2013) was used in this study as a reference due to the absence of guidelines for wastewater analysis.

In this work, QCs were used not only to support the quality of analysis, but also to ensure the safe shipment of cartridges and the analytes stability. In the light of data obtained, we could conclude that quality control along all the steps of analysis, including sample treatment, shipment of samples from Colombia to Spain, and final measurement by LC-MS/MS, was ensured giving support to the reported data. 


\section{CONCLUSIONS}

A comprehensive study applying WBE on the most frequently consumed illicit drugs has been performed for the first time in Colombia. Normalized mass loads of cocaine and BE were high and stable throughout the week, particularly in Medellin. This reflects high and regular use of cocaine by the population. The use of cannabis, MDMA and ketamine were relatively low in comparison with other countries around the world and no detectable concentrations were found for 6-MAM (heroin), methamphetamine and amphetamine. Estimation of drugs use from WBE was in general agreement with previous data reported on drug consumption in these cities, with high prevalence of cocaine and cannabis, and lower use of other substances as MDMA and ketamine. In this study, the relevance of working according to a harmonized protocol is highlighted as it allows minimizing uncertainties associated with the WBE approach. Furthermore, the need of quality control samples in collaborative studies where the samples had to be shipped overseas for analysis has been emphasized. Taking these measures into account improves the reliability of the results as well as the estimation on drug use by the population. 


\section{ACKNOWLEDGMENTS}

The authors of University Jaume I acknowledge the financial support of Generalitat Valenciana (Prometeo II 2014/023) and of the Spanish Ministry of Economy and Competitiveness (Project ref CTQ2015-65603). Dr. Lubertus Bijlsma acknowledges NPS-Euronet (HOME/2014/JDRUG/AG/DRUG/7086), co-funded by the European Union, for his post-doctoral fellowship. This publication reflects the views only of the authors, and the European Commission cannot be held responsible for any use which may be made of the information contained therein.

\section{SUPPLEMENTARY MATERIAL}

In this section, one figure, on the catchment areas of the WWTPs (Figure S1) and four tables, S1: flow data $\left(\mathrm{m}^{3} /\right.$ day) and concentrations of COD and BOD of each day/sample, S2: concentration data (ng/L) of the compounds under study in the wastewater samples, S3: total loads (g/day) of the compounds in the wastewater samples, S4: MS conditions for the LC-MS/MS measurement of the compounds under study (ion ratios and LOQs of the method), are included to have supportive visual information on the written text. 


\section{REFERENCES}

Andreottola, G., Bonomo, L., Poggiali, L., Zaffaroni, C., 1994. A methodology for the estimation of unit nutrient and organic loads from domestic and non-domestic sources. Eur. Water Pollut. Control 4, 13-19.

Baker, D.R., Kasprzyk-Hordern, B., 2011. Multi-residue analysis of drugs of abuse in wastewater and surface water by solid-phase extraction and liquid chromatographypositive electrospray ionisation tandem mass spectrometry. J. Chromatogr. A 1218, 1620-1631. doi:10.1016/j.chroma.2011.01.060

Banta-Green, C.J., Field, J.A., Chiaia, A.C., Sudakin, D.L., Power, L., De Montigny, L., 2009. The spatial epidemiology of cocaine, methamphetamine and 3,4methylenedioxymethamphetamine (MDMA) use: A demonstration using a population measure of community drug load derived from municipal wastewater. Addiction 104, 1874-1880. doi:10.1111/j.1360-0443.2009.02678.x

Been, F., Benaglia, L., Lucia, S., Gervasoni, J.P., Esseiva, P., Delémont, O., 2015. Data triangulation in the context of opioids monitoring via wastewater analyses. Drug Alcohol Depend. 151, 203-210. doi:10.1016/j.drugalcdep.2015.03.022

Been, F., Bijlsma, L., Benaglia, L., Berset, J.-D., Botero-Coy, A.M., Castiglioni, S., Kraus, L., Zobel, F., Schaub, M.P., Bücheli, A., Hernández, F., Delémont, O., Esseiva, P., Ort, C., 2016. Assessing geographical differences in illicit drug consumption - A comparison of results from epidemiological and wastewater data in Germany and Switzerland. Drug Alcohol Depend. 161, 189-199. doi:10.1016/j.drugalcdep.2016.02.002

Bijlsma, L., Beltrán, E., Boix, C., Sancho, J. V., Hernández, F., 2014. Improvements in analytical methodology for the determination of frequently consumed illicit drugs in urban wastewater. Anal. Bioanal. Chem. 406, 4261-4272. doi:10.1007/s00216-0147818-4

Bijlsma, L., Emke, E., Hernández, F., De Voogt, P., 2013. Performance of the linear ion trap Orbitrap mass analyzer for qualitative and quantitative analysis of drugs of abuse and relevant metabolites in sewage water. Anal. Chim. Acta 768, 102-110.

Bijlsma, L., Emke, E., Hernández, F., De Voogt, P., 2012. Investigation of drugs of abuse and relevant metabolites in Dutch sewage water by liquid chromatography coupled to high resolution mass spectrometry. Chemosphere 89, 1399-1406. doi:10.1016/j.chemosphere.2012.05.110

Castaño Pérez, G.A., Arango Tobon, E., Morales Mesa, S., Rodríguez Bustamante, A., Montoya Montoya, C., 2012. Consumo de drogas y prácticas sexuales de los adolescentes de la ciudad de Medellin (Colombia). Adicciones 24, 347-353.

Castaño Pérez, G.A., Calderón Vallejo, G.A., 2012. Patterns of heroin use in a sample of consumers in Medellin--Colombia. Rev. Bras. Epidemiol. 15, 504-522.

Castaño Pérez, G.A., Calderón Vallejo, G.A., Berbesi Fernandez, D.Y., 2013. Use of Emerging Drugs in Medellín, Colombia [Consumo de drogas emergentes en Medellín, Colombia]. Rev. Colomb. Psiquiatr. 42, 248-256. doi:10.1016/S00347450(13)70017-9

Castiglioni, S., Bijlsma, L., Covaci, A., Emke, E., Harman, C., Hernández, F., Kasprzyk- 
Hordern, B., Ort, C., van Nuijs, A.L.N., de Voogt, P., Zuccato, E., 2016. Estimating community drug use through wastewater-based epidemiology, in: Castiglioni, S., Vandam, L., Griffiths, P. (Eds.), Assessing Illicit Drugs in Wastewater: Advances in Wastewater-Based Drug Epidemiology, EMCDDA Insights 22. Publications Office of the European Union, Luxembourg, pp. 17-33. doi:10.2810/017397

Castiglioni, S., Bijlsma, L., Covaci, A., Emke, E., Hernández, F., Reid, M., Ort, C., Thomas, K. V., Van Nuijs, A.L.N., De Voogt, P., Zuccato, E., 2013. Evaluation of uncertainties associated with the determination of community drug use through the measurement of sewage drug biomarkers. Environ. Sci. Technol. 47, 1452-1460. doi:10.1021/es302722f

Castiglioni, S., Thomas, K. V., Kasprzyk-Hordern, B., Vandam, L., Griffiths, P., 2014. Testing wastewater to detect illicit drugs: State of the art, potential and research needs. Sci. Total Environ. 487, 613-620. doi:10.1016/j.scitotenv.2013.10.034

Charles-Edwards, E., Bell, M., 2013. Estimating the Service Population of a Large Metropolitan University Campus. Appl. Spat. Anal. Policy 6, 209-228. doi:10.1007/s12061-012-9079-y

Chiaia-Hernandez, A.C., Banta-Green, C.J., Field, J.A., 2011. Interpreting methamphetamine levels in a high-use community. Environ. Sci. Pollut. Res. 18, 1471-1477. doi:10.1007/s11356-011-0495-3

Devault, D.A., Néfau, T., Pascaline, H., Karolak, S., Levi, Y., 2014. First evaluation of illicit and licit drug consumption based on wastewater analysis in Fort de France urban area (Martinique, Caribbean), a transit area for drug smuggling. Sci. Total Environ. 490, 970-978. doi:10.1016/j.scitotenv.2014.05.090

EMCDDA, 2015a. Wastewater analysis and drugs : a European multi-city study.

EMCDDA, 2015b. European Drug Report 2015. doi:10.2810/084165

http://elsiglo.com/cronica-roja/cocaina-rosada-droga-cara-mundo/23863634 [WWW Document], el siglo. URL http://elsiglo.com/cronica-roja/cocaina-rosada-drogacara-mundo/23863634 (accessed 4.30.16).

http://score-cost.eu/ [WWW Document], URL http://score-cost.eu/ (accessed 3.18.16).

http://www.acueducto.com.co/ [WWW Document], Acueducto agua y alcantarillado Bogotá. URL http://www.acueducto.com.co/wpsv61/wps/portal (accessed 3.10.16).

http://www.emcdda.europa.eu/data/stats2015 [WWW Document], EMCDDA. URL http://www.emcdda.europa.eu/data/stats2015 (accessed 5.9.16).

http://www.epm.com.co/ [WWW Document], EPM. URL http://www.epm.com.co/ (accessed 3.10.16).

http://www.odc.gov.co/consumo-drogas-antioquia [WWW Document], Gob. Antioquia. URL http://www.odc.gov.co/Portals/1/modPublicaciones/pdf/CO03951213-suispaconsumo-drogas-antioquia-preliminar.pdf (accessed 5.9.16).

http://www.odc.gov.co/nuevas-sustancias-psicoactivas-colombia [WWW Document], ODC. URL http://www.odc.gov.co/Portals/1/encuentro-regiones/docs/10-nuevassustancias-psicoactivas-colombia.pdf (accessed 5.9.16).

https://www.unodc.org/documents/data-and-analysis/tocta/4.Cocaine

[WWW 
Document], UNODC. URL https://www.unodc.org/documents/data-andanalysis/tocta/4.Cocaine.pdf (accessed 5.9.16).

Irvine, R.J., Kostakis, C., Felgate, P.D., Jaehne, E.J., Chen, C., White, J.M., 2011. Population drug use in Australia: a wastewater analysis. Forensic Sci. Int. 210, 6973. doi:10.1016/j.forsciint.2011.01.037

Khan, U., van Nuijs, A.L.N., Li, J., Maho, W., Du, P., Li, K., Hou, L., Zhang, J., Meng, X., Li, X., Covaci, A., 2014. Application of a sewage-based approach to assess the use of ten illicit drugs in four Chinese megacities. Sci. Total Environ. 487, 710-721. doi:10.1016/j.scitotenv.2014.01.043

Kim, K.Y., Lai, F.Y., Kim, H.-Y., Thai, P.K., Mueller, J.F., Oh, J.-E., 2015. The first application of wastewater-based drug epidemiology in five South Korean cities. Sci. Total Environ. 524-525, 440 - 446. doi:10.1016/j.scitotenv.2015.04.065

Kinyua, J., Covaci, A., Maho, W., McCall, A.-K., Neels, H., van Nuijs, A.L.N., 2015. Sewage-based epidemiology in monitoring the use of new psychoactive substances: Validation and application of an analytical method using LC-MS/MS. Drug Test. Anal. 7, 812-818. doi:10.1002/dta.1777

Lai, F.Y., Bruno, R., Leung, H.W., Thai, P.K., Ort, C., Carter, S., Thompson, K., Lam, P.K.S., Mueller, J.F., 2013. Estimating daily and diurnal variations of illicit drug use in Hong Kong: A pilot study of using wastewater analysis in an Asian metropolitan city. Forensic Sci. Int. 233, 126-132. doi:10.1016/j.forsciint.2013.09.003

Lai, F.Y., Ort, C., Gartner, C., Carter, S., Prichard, J., Kirkbride, P., Bruno, R., Hall, W., Eaglesham, G., Mueller, J.F., 2011. Refining the estimation of illicit drug consumptions from wastewater analysis: co-analysis of prescription pharmaceuticals and uncertainty assessment. Water Res. 45, 4437-4448. doi:10.1016/j.watres.2011.05.042

Lin, A.Y.-C., Wang, X.-H., Lin, C.-F., 2010. Impact of wastewaters and hospital effluents on the occurrence of controlled substances in surface waters. Chemosphere 81, 562570. doi:10.1016/j.chemosphere.2010.08.051

Maldaner, A.O., Schmidt, L.L., Locatelli, M.A.F., Jardim, W.F., Sodré, F.F., Almeida, F. V., Pereira, C.E.B., Silva, C.M., 2012. Estimating cocaine consumption in the brazilian federal district (FD) by sewage analysis. J. Braz. Chem. Soc. 23, 861-867. doi:10.1590/S0103-50532012000500011

McCall, A.-K., Bade, R., Kinyua, J., Lai, F.Y., Thai, P.K., Covaci, A., Bijlsma, L., van Nuijs, A.L.N., Ort, C., 2016. Critical review on the stability of illicit drugs in sewers and wastewater samples. Water Res. 88, 933-947. doi:10.1016/j.watres.2015.10.040

Metcalfe, C., Tindale, K., Li, H., Rodayan, A., Yargeau, V., 2010. Illicit drugs in Canadian municipal wastewater and estimates of community drug use. Environ. Pollut. 158, 3179-3185. doi:10.1016/j.envpol.2010.07.002

O’Brien, J.W., Thai, P.K., Eaglesham, G., Ort, C., Scheidegger, A., Carter, S., Lai, F.Y., Mueller, J.F., 2013. A Model to Estimate the Population Contributing to the Wastewater Using Samples Collected on Census Day. Environ. Sci. Technol. 48, 517-525. doi:10.1021/es403251g

Ort, C., Lawrence, M.G., Rieckermann, J., Joss, A., 2010. Sampling for pharmaceuticals 
and personal care products (PPCPs) and illicit drugs in wastewater systems: Are your conclusions valid? A critical review. Environ. Sci. Technol. 44, 6024-6035. doi:10.1021/es100779n

Ort, C., van Nuijs, A.L.N., Berset, J.D., Bijlsma, L., Castiglioni, S., Covaci, A., de Voogt, P., Emke, E., Fatta-Kassinos, D., Griffiths, P., Hernández, F., González-Mariño, I., Grabic, R., Kasprzyk-Hordern, B., Mastroianni, N., Meierjohann, A., Nefau, T., Östman, M., Pico, Y., Racamonde, I., Reid, M., Slobodnik, J., Terzic, S., Thomaidis, N., Thomas, K. V., 2014. Spatial differences and temporal changes in illicit drug use in Europe quantified by wastewater analysis. Addiction 109, 1338-1352. doi:10.1111/add.12570

Prichard, J., Lai, F.Y., Kirkbride, P., Bruno, R., Ort, C., Carter, S., Hall, W., Gartner, C., Thai, P.K., Mueller, J.F., 2012. Measuring drug use patterns in Queensland through wastewater analysis. Trends Issues Crime Crim. Justice 1-8.

Reid, M.J., Langford, K.H., Mørland, J., Thomas, K. V., 2011. Analysis and interpretation of specific ethanol metabolites, ethyl sulfate, and ethyl glucuronide in sewage effluent for the quantitative measurement of regional alcohol consumption. Alcohol. Clin. Exp. Res. 35, 1593-1599. doi:10.1111/j.1530-0277.2011.01505.x

Rodriguez-Alvarez, T., Rodil, R., Rico, M., Cela, R., Quintana, J.B., 2014. Assessment of Local Tobacco Consumption by Liquid Chromatography - Tandem Mass Spectrometry Sewage Analysis of Nicotine and Its Metabolites, Cotinine and trans3 ' -Hydroxycotinine, after Enzymatic Deconjugation. Anal. Chemsitry 86, 1027410281.

Sabogal-Carmona, J., Urrego-Novoa, J., 2012. Composición química de muestras de bazuco incautado en Colombia primer semestre de 2010. Rev. salud pública 14, $1014-1025$.

Salvatore, S., Bramness, J.G., Reid, M.J., Thomas, K. V., Harman, C., Roislien, J., 2015. Wastewater-Based Epidemiology of Stimulant Drugs: Functional Data Analysis Compared to Traditional Statistical Methods. PLoS One 1-14. doi:DOI:10.1371/journal.pone.0138669

SANCO, 2013. Guidance document on analytical quality control and validation procedures for pesticide residues analysis in food and feed.

Subedi, B., Kannan, K., 2014. Mass loading and removal of select illicit drugs in two wastewater treatment plants in New York State and estimation of illicit drug usage in communities through wastewater analysis. Environ. Sci. Technol. 48, 6661-6670. doi:10.1021/es501709a

Thomas, K. V., Bijlsma, L., Castiglioni, S., Covaci, A., Emke, E., Grabic, R., Hernández, F., Karolak, S., Kasprzyk-Hordern, B., Lindberg, R.H., Lopez de Alda, M., Meierjohann, A., Ort, C., Pico, Y., Quintana, J.B., Reid, M., Rieckermann, J., Terzic, S., van Nuijs, A.L.N., de Voogt, P., 2012. Comparing illicit drug use in 19 European cities through sewage analysis. Sci. Total Environ. 432, 432-439. doi:10.1016/j.scitotenv.2012.06.069

UNODC, 2015. World Drug Report 2015, Trends in Organized Crime. doi:10.1007/s13398-014-0173-7.2

UNODC, 2014. World Drug Report 2014, Trends in Organized Crime. 
doi:10.1007/s12117-997-1166-0

van Nuijs, A.L.N., Castiglioni, S., Tarcomnicu, I., Postigo, C., de Alda, M.L., Neels, H., Zuccato, E., Barcelo, D., Covaci, A., 2011a. Illicit drug consumption estimations derived from wastewater analysis: A critical review. Sci. Total Environ. 409, 35643577. doi:10.1016/j.scitotenv.2010.05.030

van Nuijs, A.L.N., Gheorghe, A., Jorens, P.G., Maudens, K., Neels, H., Covaci, A., 2014. Optimization, validation, and the application of liquid chromatography-tandem mass spectrometry for the analysis of new drugs of abuse in wastewater. Drug Test. Anal. 6, 861-867. doi:10.1002/dta.1460

van Nuijs, A.L.N., Mougel, J.-F., Tarcomnicu, I., Bervoets, L., Blust, R., Jorens, P.G., Neels, H., Covaci, A., 2011b. Sewage epidemiology--a real-time approach to estimate the consumption of illicit drugs in Brussels, Belgium. Environ. Int. 37, 612621. doi:10.1016/j.envint.2010.12.006

Yargeau, V., Taylor, B., Li, H., Rodayan, A., Metcalfe, C.D., 2014. Analysis of drugs of abuse in wastewater from two Canadian cities. Sci. Total Environ. 487, 722-730. doi:10.1016/j.scitotenv.2013.11.094

Zuccato, E., Chiabrando, C., Castiglioni, S., Calamari, D., Bagnati, R., Schiarea, S., Fanelli, R., 2005. Cocaine in surface waters: a new evidence-based tool to monitor community drug abuse. Environ. Heal. A Glob. Access Sci. Source 4, 1-7. doi:10.1186 
Table 1. Normalized mass loads (mg/day/1000 inhabitants) of the compounds in wastewater

\begin{tabular}{|c|c|c|c|c|c|c|c|c|}
\hline Cities & Compound & Wednesday & Thursday & Friday & Saturday & Sunday & Monday & Tuesday \\
\hline \multirow{5}{*}{ Bogotá } & Cocaine & 87 & 98 & 95 & 114 & 94 & 79 & 9.1 \\
\hline & Benzoylecgonine & 206 & 211 & 203 & 243 & 223 & 166 & 196 \\
\hline & MDMA & 1.7 & 2.9 & 4.6 & 8.5 & 9.9 & 2.9 & 1.7 \\
\hline & $\mathrm{THC}-\mathrm{COOH}$ & 38 & 38 & 33 & 31 & 30 & 27 & 28 \\
\hline & Ketamine & 4.0 & 4.7 & 2.9 & 3.4 & 3.5 & 3.5 & 4.0 \\
\hline & & & & & & & & \\
\hline \multirow{5}{*}{ Medellín } & Cocaine & 9.9 & 11 & 48 & 47 & 58 & 162 & 25 \\
\hline & Benzoylecgonine & 809 & 863 & 893 & 965 & 811 & 765 & 786 \\
\hline & MDMA & n.d & n.d & n.d & n.d & 1.6 & 1.7 & 1.3 \\
\hline & THC-COOH & 44 & 46 & 44 & 50 & 45 & 46 & 53 \\
\hline & Ketamine & 2.0 & 1.3 & 1.3 & 1.9 & 1.6 & 1.1 & 1.3 \\
\hline
\end{tabular}


4 Table 2. Back-calculation of cocaine consumption by the population (mg/day/1000 inh.) from BE loads in wastewater

6

7

8

9

10

11

12

13

\begin{tabular}{l|c|r}
\hline Day & Bogotá & Medellín \\
\hline Wednesday & 741 & 2906 \\
Thursday & 757 & 3098 \\
Friday & 728 & 3205 \\
Saturday & 871 & 3465 \\
Sunday & 799 & 2910 \\
Monday & 597 & 2747 \\
Tuesday & 703 & 2823 \\
\hline Weekly Average & $\mathbf{7 4 2}$ & $\mathbf{3 0 2 2}$ \\
\hline
\end{tabular}

14 
Table 3. Quality control samples analysed in every batch of samples from Bogota and Medellin: recovery values and ion ratio deviations (\%)

\begin{tabular}{|c|c|c|c|c|c|c|c|c|}
\hline Compound & City & $\begin{array}{c}\mathrm{QC} \\
(\mu \mathrm{g} / \mathrm{L})\end{array}$ & $\begin{array}{c}\text { Found in non-spiked } \\
\text { sample }(\mu \mathrm{g} / \mathrm{L})\end{array}$ & $\begin{array}{c}\text { Found in spiked } \\
\text { sample }(\mu \mathrm{g} / \mathrm{L})\end{array}$ & $\begin{array}{c}\text { Difference }^{\mathrm{a}} \\
(\mu \mathrm{g} / \mathrm{L})\end{array}$ & $\begin{array}{c}\text { Recovery } \\
(\%)\end{array}$ & $\mathrm{q}_{1} / \mathrm{Q} \operatorname{dev}(\%)$ & $\begin{array}{c}\mathrm{q}_{2} / \mathrm{Q} \text { dev } \\
(\%)\end{array}$ \\
\hline \multirow{4}{*}{ Amphetamine } & & 0.1 & \multirow[t]{4}{*}{ 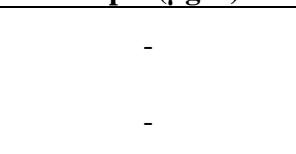 } & 0.10 & 0.10 & 100 & 35 & 14 \\
\hline & Bogota & 0.8 & & 0.98 & 0.98 & 123 & -19 & 15 \\
\hline & & 0.1 & & 0.12 & 0.12 & 120 & -63 & 56 \\
\hline & Medellin & 0.8 & & 0.87 & 0.87 & 109 & -15 & 32 \\
\hline \multirow{4}{*}{ Methamphetamine } & 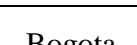 & 0.1 & \multirow{2}{*}{ - } & 0.09 & 0.09 & 90 & -8 & -39 \\
\hline & Bogota & 0.8 & & 0.70 & 0.70 & 88 & -3 & 3 \\
\hline & & 0.1 & \multirow[b]{2}{*}{-} & 0.10 & 0.10 & 100 & 11 & -50 \\
\hline & Medellin & 0.8 & & 0.69 & 0.69 & 86 & -1 & -16 \\
\hline \multirow{4}{*}{ MDMA } & & 0.1 & \multirow{4}{*}{0.02} & 0.11 & 0.09 & 90 & -9 & -15 \\
\hline & Bogota & 0.8 & & 0.71 & 0.69 & 86 & -8 & -18 \\
\hline & & 0.1 & & 0.08 & 0.08 & 80 & -12 & -11 \\
\hline & Medellin & 0.8 & & 0.55 & 0.55 & 69 & -10 & -13 \\
\hline \multirow{4}{*}{ Cocaine } & Bogota & 0.1 & \multirow[t]{2}{*}{0.54} & 0.65 & 0.11 & 110 & -10 & 3 \\
\hline & & 0.8 & & 1.50 & 0.96 & 120 & -6 & 0 \\
\hline & Medellin & 0.1 & \multirow[t]{2}{*}{0.15} & 0.26 & 0.11 & 110 & -12 & -7 \\
\hline & & 0.8 & & 1.00 & 0.85 & 106 & -8 & -1 \\
\hline \multirow{4}{*}{ Benzoylecgonine $^{b}$} & & 0.1 & \multirow{2}{*}{1.15} & 1.31 & - & - & 10 & 17 \\
\hline & Bogota & 0.8 & & 2.05 & 0.90 & 113 & 8 & 14 \\
\hline & & 0.1 & \multirow{2}{*}{4.78} & 4.70 & - & - & 8 & 22 \\
\hline & Medellin & 0.8 & & 5.02 & - & - & 2 & 12 \\
\hline \multirow{4}{*}{ THC-СОOH } & & 0.1 & \multirow{2}{*}{0.18} & 0.29 & 0.11 & 110 & 12 & 20 \\
\hline & Bogota & 0.8 & & 0.94 & 0.76 & 95 & 13 & -3 \\
\hline & & 0.1 & \multirow{2}{*}{0.32} & 0.35 & 0.03 & 30 & 13 & 17 \\
\hline & Medellin & 0.8 & & 0.98 & 0.66 & 83 & 9 & 7 \\
\hline \multirow{4}{*}{ 6-МАМ } & & 0.1 & \multirow{4}{*}{ - } & 0.14 & 0.14 & 140 & 7 & 23 \\
\hline & Bogota & 0.8 & & 0.90 & 0.90 & 113 & -7 & -6 \\
\hline & & 0.1 & & 0.15 & 0.15 & 150 & 1 & 19 \\
\hline & Medellin & 0.8 & & 0.92 & 0.92 & 115 & -13 & -7 \\
\hline \multirow{4}{*}{ Ketamine } & & 0.1 & \multirow{4}{*}{0.02} & 0.11 & 0.09 & 90 & -9 & -9 \\
\hline & & 0.8 & & 0.74 & 0.72 & 90 & -4 & -7 \\
\hline & Medellin & 0.1 & & 0.10 & 0.10 & 100 & -10 & 1 \\
\hline & & 0.8 & & 0.74 & 0.74 & 90 & -12 & -7 \\
\hline
\end{tabular}

a The difference between the non-spiked sample and the spiked sample

${ }^{\mathrm{b}}$ Only one data was available for BE due to the high concentrations found in the "blank" non-spiked samples 
Figure captions

19

Figure 1. UHPLC-MS/MS chromatograms for positive finding in sewage of Bogotá, THC-COOH and ketamine (A), and cocaine and benzoylecgonine for Medellin 22 (B).

23

Figure 2. Normalized loads mg/day/1000 inhabitants in wastewater of Bogotá and Medellin (A) cocaine, BE (B) ketamine, MDMA, THC-COOH over 7 consecutive sampling days. 

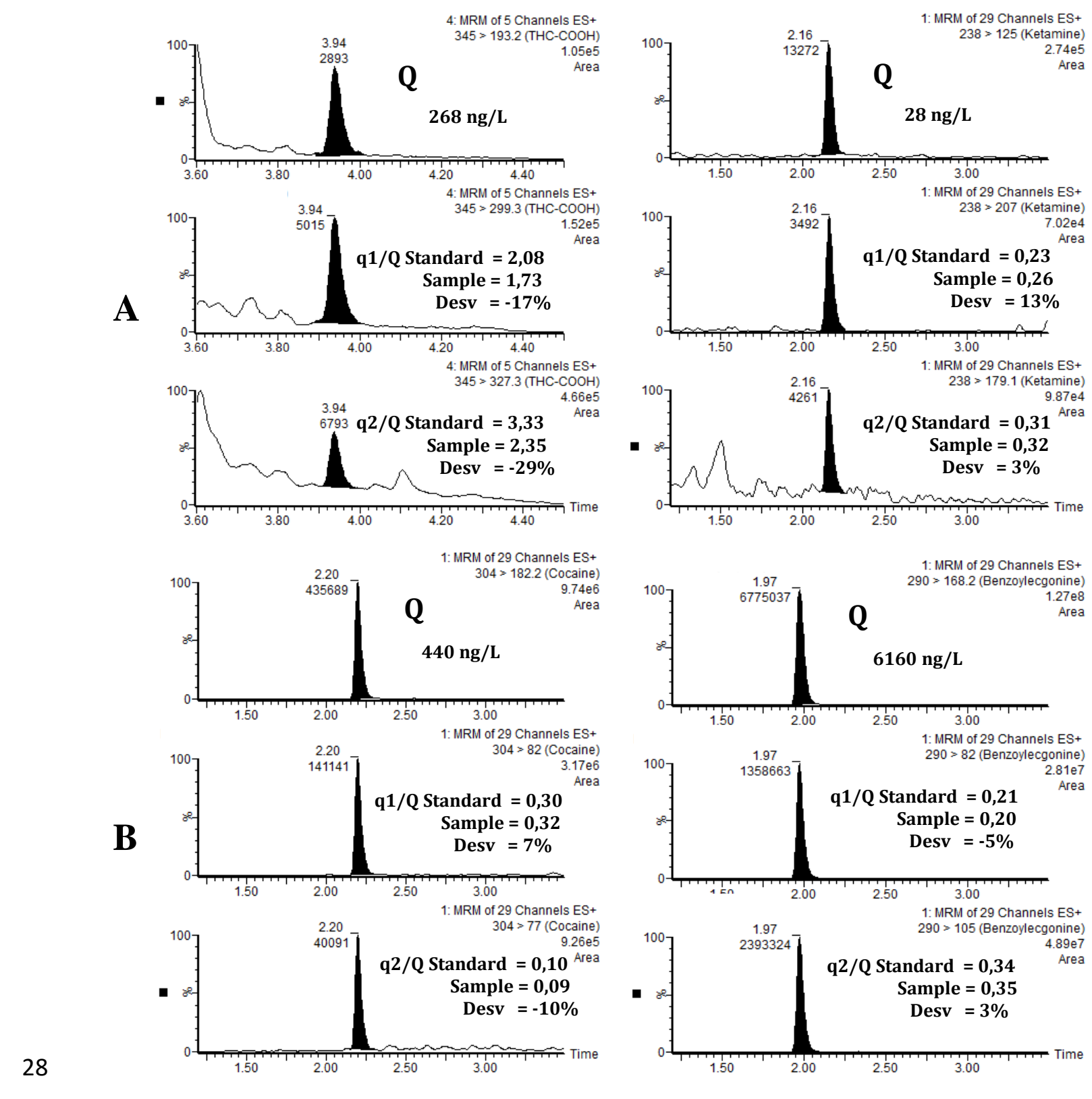

Figure 1 


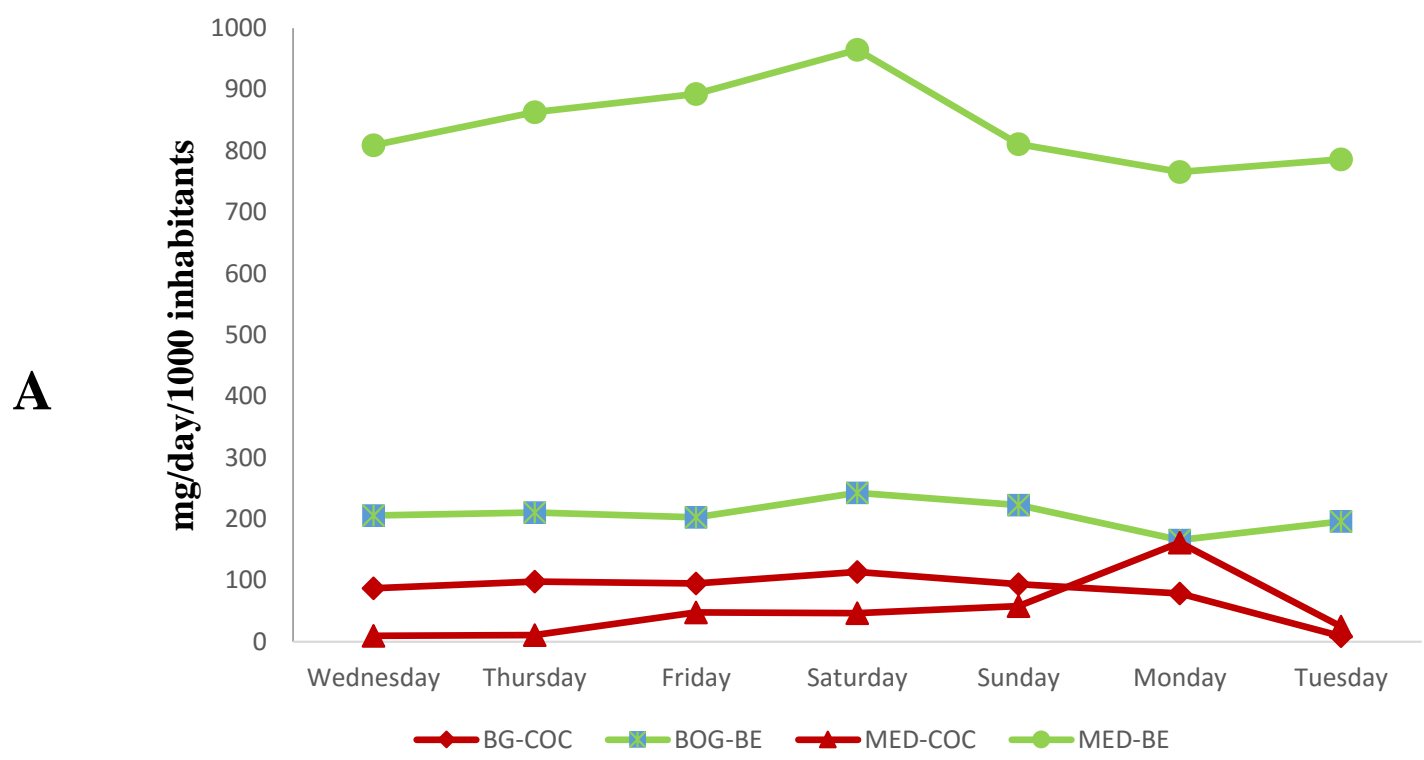

31

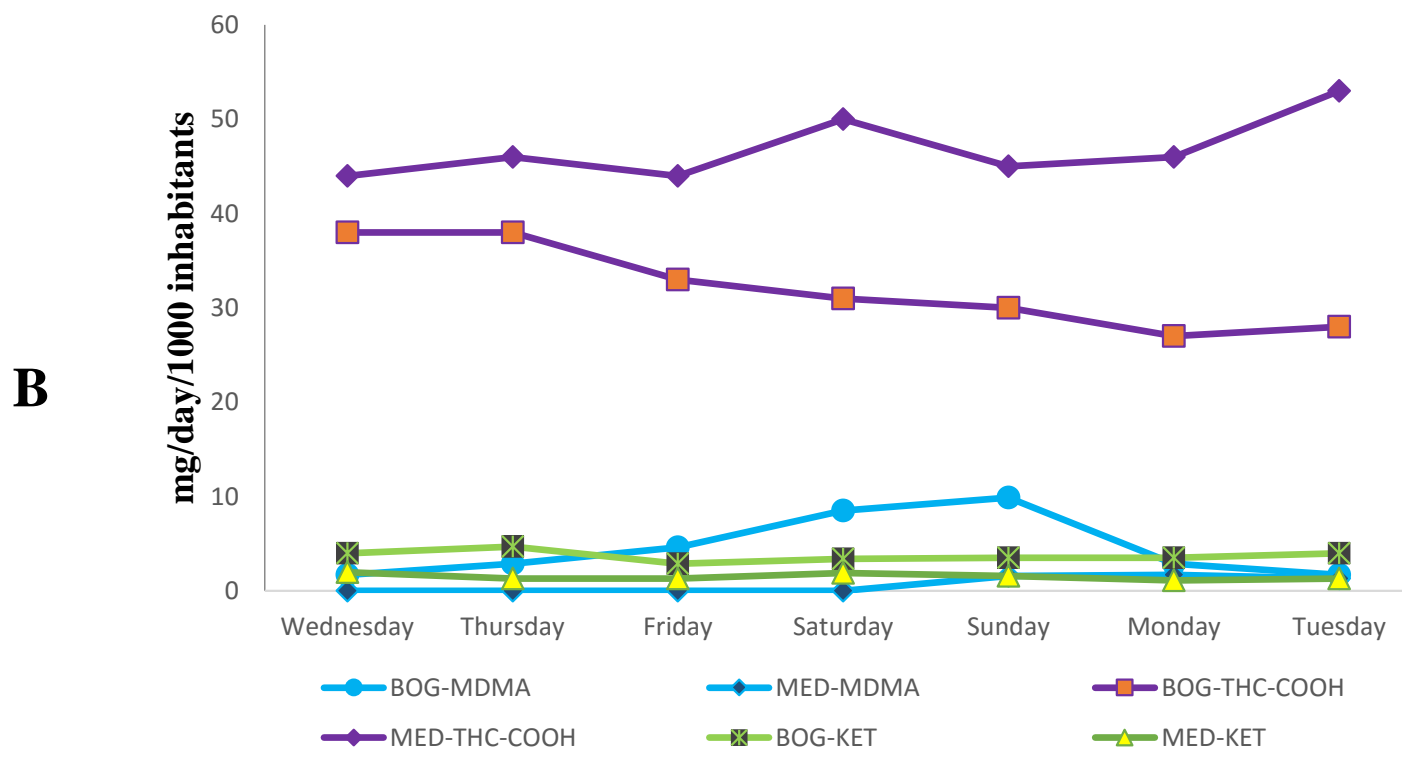

32

$33 \quad$ Figure 2 